Research Paper

\title{
Screening for Fabry Disease by Urinary Globotriaosylceramide Isoforms Measurement in Patients with Left Ventricular Hypertrophy
}

\author{
Martina Gaggl 1,2, Natalija Lajic 1, Georg Heinze 3, Till Voigtländer 4, Raute Sunder-Plassmann 5, Eduard \\ Paschke 6, Günter Fauler 7, Gere Sunder-Plassmann 2, Gerald Mundigler ${ }^{1}{ }^{\circledR}$ \\ 1. Department of Medicine II, Division of Cardiology, Medical University of Vienna, Währinger Gürtel 18-20, 1090 Vienna, Austria. \\ 2. Department of Medicine III, Division of Nephrology and Dialysis, Medical University of Vienna, Währinger Gürtel 18-20, 1090 Vienna, Austria. \\ 3. Center of Medical Statistics, Informatics and Intelligent Systems, Medical University of Vienna, Währinger Gürtel 18-20, 1090 Vienna, Austria. \\ 4. Department of Clinical Neurology, Medical University of Vienna, Währinger Gürtel 18-20, 1090 Vienna, Austria. \\ 5. Department of Laboratory Medicine, Laboratory for Molecular Diagnostics, Medical University of Vienna, Währinger Gürtel 18-20, 1090 Vienna, Austria. \\ 6. Department of Pediatrics, Medical University of Graz, Auenbruggerplatz, $8036 \mathrm{Graz}$, Austria. \\ 7. Clinical Institute of Medical and Chemical Laboratory Diagnostics, Medical University of Graz, Auenbruggerplatz, 8036 Graz, Austria.
}

$\square$ Corresponding author: Gerald Mundigler, MD, Department of Medicine II, Division of Cardiology, Medical University of Vienna, Währinger Gürtel 18-20, 1090 Vienna, Austria. Tel.: +43 40400 46140; Fax.: +43 40400 46240; E-Mail: gerald.mundigler@meduniwien.ac.at

( ) Ivyspring International Publisher. Reproduction is permitted for personal, noncommercial use, provided that the article is in whole, unmodified, and properly cited. See http://ivyspring.com/terms for terms and conditions.

Received: 2016.01.17; Accepted: 2016.03.21; Published: 2016.04.26

\begin{abstract}
Background: Left ventricular hypertrophy $(\mathrm{LVH})$ is a frequent echocardiographic feature in Fabry disease (FD) and in severe cases may be confused with hypertrophic cardiomyopathy (HCM) of other origin. The prevalence of FD in patients primarily diagnosed with HCM varies considerably in screening and case finding studies, respectively. In a significant proportion of patients, presenting with only mild or moderate $\mathrm{LVH}$ and unspecific clinical signs FD may remain undiagnosed. Urinary $\mathrm{Gb}_{3}$ isoforms have been shown to detect FD in both, women and men. We examined whether this non-invasive method would help to identify new FD cases in a non-selected cohort of patients with various degree of $\mathrm{LVH}$.

Methods and results: Consecutive patients older than 18 years with a diastolic interventricular septal wall thickness of $\geq 12 \mathrm{~mm}$ determined by echocardiography were included. Referral diagnosis was documented and spot urine was collected. $\mathrm{Gb}_{3}$ was measured by mass spectroscopy. Subjects with an elevated $\mathrm{Gb}_{3}-24: 18$ ratio were clinically examined for signs of FD, $\alpha$-galactosidase-A activity in leukocytes was determined and GLA-mutation-analysis was performed. We examined 2596 patients. In 99 subjects urinary Gb3 isoforms excretion were elevated. In these patients no new cases of FD were identified by extended FD assessment. In two of three patients formerly diagnosed with FD Gb3-24:18 ratio was elevated and would have led to further diagnostic evaluation.

Conclusion: Measurement of urinary Gb3 isoforms in a non-selected cohort with LVH was unable to identify new cases of FD. False positive results may be prevented by more restricted inclusion criteria and may improve diagnostic accuracy of this method.
\end{abstract}

Key words: Fabry disease, left ventricular hypertrophy, case-finding study, urinary $\mathrm{Gb}_{3}$ isoforms

\section{Background}

Fabry disease (FD) is a rare $\mathrm{X}$-linked lysosomal storage disorder with reduced or absent activity of $\alpha$-galactosidase-A (AGAL) and consecutive accumulation of globotriaosylceramide $\left(\mathrm{Gb}_{3}\right)$ in various organs, predominantly within the kidneys, the heart and the central nervous system [1]. Frequently, FD patients present with unspecific clinical signs and the mean delay from onset of the 
first symptoms to a definite diagnosis is 13.7 years [2]. Cardiologists diagnose only five percent of FD patients. An early diagnosis could lead to the initiation of specific treatment and prevent disease progression [3]. Therefore, experts suggested systematic screening and case-finding concepts for populations at risk [4-6].

Progressive left ventricular hypertrophy (LVH) is a common feature in FD [1] and the prevalence of FD in screened cohorts with unexplained LVH or hypertrophic cardiomyopathy ranged between zero and $12 \%$ [7-15]. However, patients with FD presenting with mild to moderate $\mathrm{LVH}$, were often excluded in screening studies $[16,17]$. In these studies cases of FD may remain undiagnosed due to selection bias [15]. While enzymatic and genetic testing are the first choice in patients with clinically suspected FD, measurement of urinary $\mathrm{Gb}_{3}$ isoforms could serve as a non-invasive and cost-effective method for a primary screening in large cohorts at risk [18,19]. We aimed to examine a clinically non-selected cohort of patients with a various degree of $\mathrm{LVH}$ for FD by measuring urinary $\mathrm{Gb}_{3}$ isoforms.

\section{Materials and methods}

\section{Study population}

Patients consecutively referred for an echocardiographic examination to the outpatient service of the Department of Cardiology at the Medical University of Vienna and eligible for study participation were included. Inclusion criteria was an echocardiographically established diagnosis of LVH, defined as left ventricular wall thickness of $\geq 12 \mathrm{~mm}$ and age over 18 years. Patients were not prescreened with respect to common FD signs or symptoms. From patients willing to participate in the study urine samples were collected. Subjects previously diagnosed with FD, which met the inclusion criteria, were included in the study, but separately statistically analyzed.

All subjects gave informed consent, the ethics committee approved the study (ClinicalTrails.gov identifier: NCT00871611), and the study was conducted in accordance with the Declaration of Helsinki.

\section{Echocardiography}

Two-dimensional echocardiography was performed with the Vivid Seven (GE, Vingmed Ultrasound AS, Horten, Norway) or the Acuson Sequoia C512 (Acuson Inc., Mountain View, CA, USA). Septal- and posterior wall thickness was evaluated at standard M-mode at the midpapillary parasternal short axis view and, if not otherwise obtainable, interventricular septum (IVS) thickness was measured in the apical four-chamber view.

\section{Laboratory measurements}

Spot urine samples $(10 \mathrm{~mL})$ were stored in Sarstedt Monovette tubes (10 mL, Nr. 10252; Sarstedt AG\&Co. Nümbrecht, Germany) at four degrees Celsius and shipped to the Laboratory of Metabolic Diseases at the Department of Pediatrics at the Medical University of Graz (E. P.) no longer than 14 days before analyzed. After the addition of $0.01 \%$ sodium acid samples were stored at minus 70 degrees Celsius until use.

\section{Direct ESI-MS of urinary glycolipids}

Samples were processed for measurement with electrospray ionization mass spectrometry (ESI-MS) as previously described [20]. In brief, internal standard (stearoyl- $\mathrm{Gb}_{3}-\mathrm{d}_{35}$ ) was added to $5 \mathrm{ml}$ aliquots of samples and glycolipids were purified by solid-phase extraction on $\mathrm{C}_{18}$ bonded silica cartridges. Glycolipids were measured as positive ions using full scan and neutral loss scan modes exactly as described $[19,20]$. Total $\mathrm{Gb}_{3}$, as well as the isoforms $\mathrm{Gb}_{3}-24$ and $\mathrm{Gb}_{3}-18$, are given in nanograms per milligrams of urinary creatinine (total $\mathrm{Gb}_{3}$ :creatinine, $\mathrm{Gb}_{3}$-24:creatinine and, $\mathrm{Gb}_{3}-18$ :creatinine). The ratio of the isoforms $\mathrm{Gb}_{3}-24$ :creatinine and $\mathrm{Gb}_{3}-18$ :creatinine $\left(\mathrm{Gb}_{3}-24: 18\right)$ was used for screening procedures.

The full scan spectra of all samples were visually evaluated (G.F.) for plausibility of quantitation [19]. Quantitation of chromatograms, in which the peak height of the internal standard $(\mathrm{m} / \mathrm{z}=1109.9)$ was less than twice the average background were discarded (uncertain analytical performance, UAP) [19].

\section{Confirmation testing}

Subjects with a urinary $\mathrm{Gb}_{3}$ concentration exceeding the predefined cut-off $\left(\mathrm{Gb}_{3}-24: 18\right.$ ratio > 2.3) were classified to be at risk for Fabry disease. The AGAL activity was tested and GLA-mutation-analysis was performed as previously described (4). Medical history and family history were determined by questionnaire. Subjects not available for confirmation testing (not interested, not available, deceased) were investigated as detailed as possible by means of medical charts.

\section{Statistical Analysis}

Continuous data are described by mean \pm standard deviation (SD) or median and inter quartile range (IQR), categorical data are presented as count and percentage.

P-values lower than 0.05 were considered as indicating statistical significance. PASW Statistics 18 software (IBM) was used for statistical computations. 


\section{Results}

\section{Study population}

In total, 2676 subjects were included in the study, of which 80 subjects were excluded due to double inclusion and three subjects had a previously established diagnosis of FD (figure 1). The finally screened study cohort consisted of 2596 patients. Demographic details about the study population are given in table 1.

\section{Case-finding study and confirmatory tests}

In 2596 patients the urinary $\mathrm{Gb}_{3}$ concentration could be determined, of which 2494 (96\%) were classified as unremarkable. The mean total urinary $\mathrm{Gb}_{3}$ :creatinine concentration was 236.8 (SD=175.5) $\mathrm{ng} / \mathrm{mg}$, the urinary $\mathrm{Gb}_{3}-24$ :creatinine concentration was $38.7(\mathrm{SD}=29.3) \mathrm{ng} / \mathrm{mg}$, and the mean urinary $\mathrm{Gb}_{3}-24: 18$ ratio was $1.34(\mathrm{SD}=0.74)$ (figure $2(\mathrm{~A}),(\mathrm{B})$, and $(\mathrm{C})$ ). Ninety-nine (4\%) subjects showed an elevated urinary $\mathrm{Gb}_{3}-24: 18$ isoform ratio (mean 3.48 $(\mathrm{SD}=2.63)$ and were invited for an additional visit to evaluate the medical history and clinical symptoms, to test for GLA mutations and to determine the AGAL activity in leukocytes. Eight subjects withdrew informed consent for genetic testing, in 16 no contact could be established after several attempts, and 4 patients were deceased at that time. Chart review of those 28 subjects did not show any specific hints with regard to FD, definite exclusion of this diagnosis however was unfeasible. All remaining 71 subjects had a wild-type GLA gene and the mean AGAL activity was $101.5(\mathrm{SD}=29.8) \mathrm{nMol} / \mathrm{mg}$ prot/h.

\section{Previously diagnosed Fabry patients}

Three diagnosed FD patients meeting the inclusion criteria (table 2), of which two brothers with a classic phenotype could be identified by the screening method. The women with an unknown genetic alteration and AGAL activity within normal limits, but classic symptoms of FD, had a normal urinary Gb3 excretion, determined in the 24-hour urine collection and by means of the applied method.

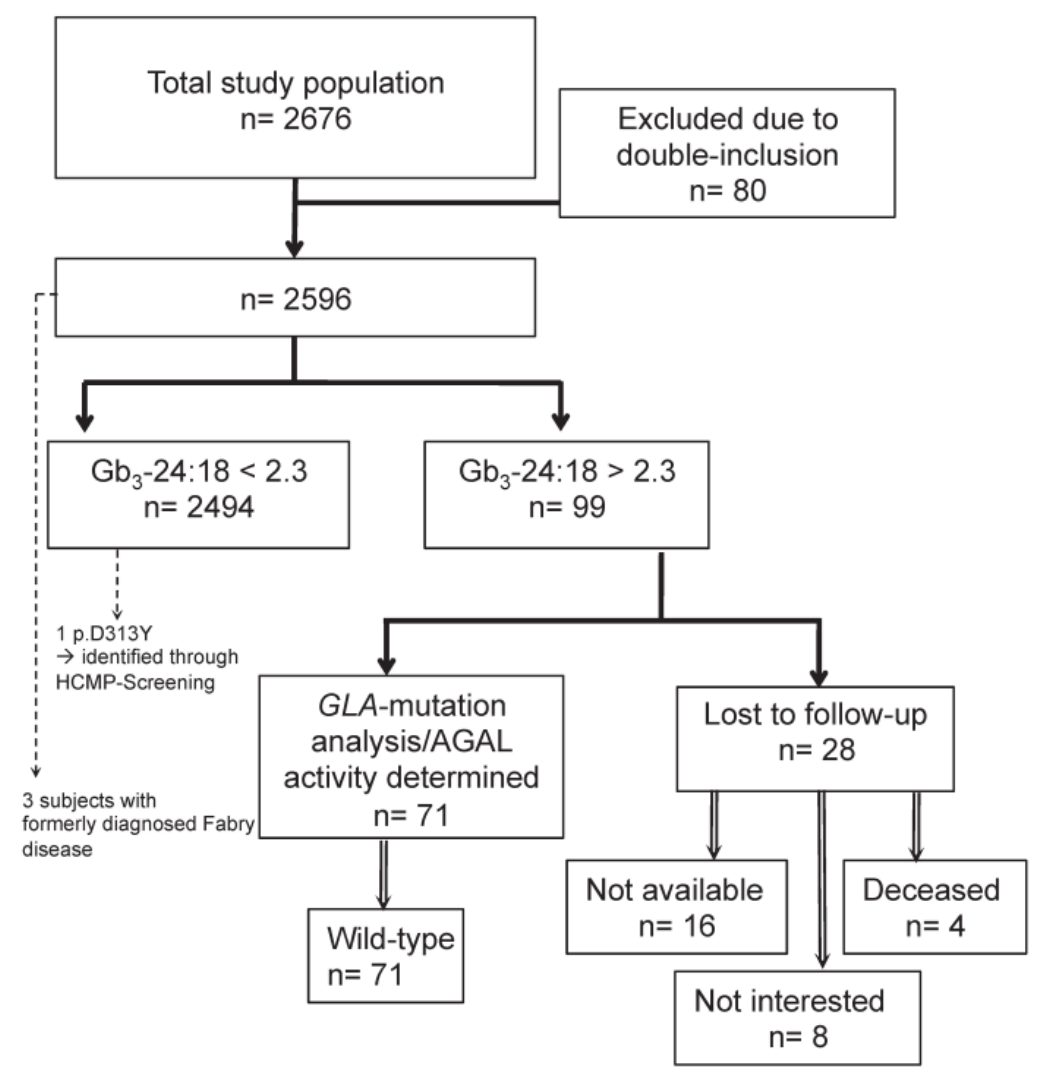

Figure 1. Study-population 

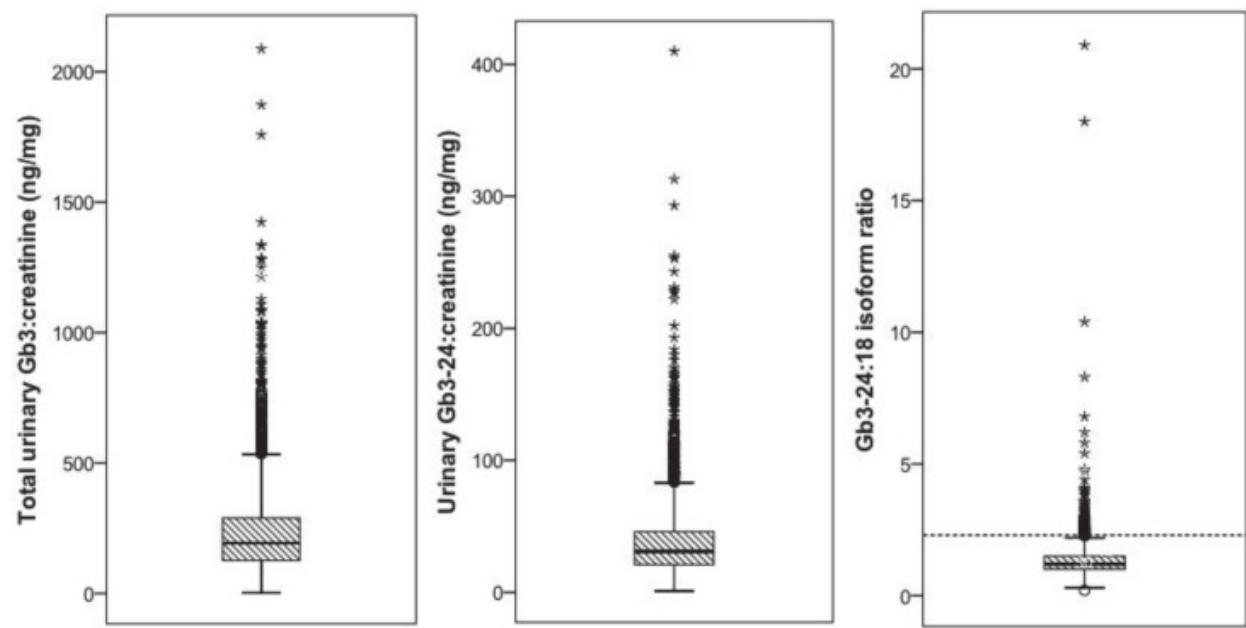

Figure 2. Total urinary Gb3:creatinine (A), Gb3-24:creatinine (B), and the Gb3-24:18 ratio in 2494 subjects. The dashed line in panel (C) indicates the suggested critical cut-off value of $2.3 \mathrm{ng} / \mathrm{mg}$ for subjects suspicious for Fabry disease.

Table 1. Study population (mean $( \pm S D)$ or count (percent)).

\begin{tabular}{|c|c|c|c|}
\hline \multirow[b]{2}{*}{$\mathrm{N}$} & All & $\mathrm{Gb}_{3}-24: 18 \uparrow$ & $\mathrm{Gb}_{3}-24: 18 \perp$ \\
\hline & $2593^{*}$ & $99 \quad(4)$ & $2494(96)$ \\
\hline Sex (female) & $907 \quad(35)$ & $23 \quad(3)$ & $884(97)$ \\
\hline Age (years) & $64( \pm 20)$ & $63( \pm 13)$ & $64( \pm 20)$ \\
\hline \multicolumn{4}{|l|}{ Referral diagnosis: } \\
\hline Valvular disease & $733(28)$ & $31(31)$ & $702(28)$ \\
\hline Coronary artery disease & $379(15)$ & 19 (19) & $360(14)$ \\
\hline Arterial hypertension & $280(11)$ & $6 \quad(6)$ & $274(11)$ \\
\hline Hypertrophic CMP & $68 \quad(3)$ & 3 (3) & $65 \quad(3)$ \\
\hline Dilated CMP & $49 \quad(2)$ & 2 (2) & $47 \quad(2)$ \\
\hline Ischemic CMP & $11(0.4)$ & 0 & $11(0.4)$ \\
\hline Heart transplant & $61 \quad(2)$ & $1 \quad(1)$ & $60 \quad(1)$ \\
\hline Others & 1008 (39) & $37(37)$ & 971 (39) \\
\hline
\end{tabular}

IVS thickness:

\begin{tabular}{|c|c|c|c|}
\hline $12 \mathrm{~mm}$ & 614 (24) & $23(23)$ & $591(24)$ \\
\hline $13 \mathrm{~mm}$ & 693 (27) & $23(23)$ & $670(27)$ \\
\hline $14 \mathrm{~mm}$ & $546(21)$ & $23(23)$ & $523(21)$ \\
\hline $15 \mathrm{~mm}$ & $246 \quad(9)$ & 13 (13) & 233 \\
\hline $16 \mathrm{~mm}$ & $177 \quad(7)$ & $3 \quad(3)$ & 174 \\
\hline $17 \mathrm{~mm}$ & 114 & $8 \quad(8)$ & 106 \\
\hline $18 \mathrm{~mm}$ & $76 \quad(3)$ & (4) & 72 \\
\hline$>18 \mathrm{~mm}$ & $127 \quad(5)$ & $2 \quad(2)$ & $125 \quad(5)$ \\
\hline
\end{tabular}

* 3 positive controls were excluded.

Urinary $\mathrm{Gb}_{3} \uparrow$, elevated urinary $\mathrm{Gb}_{3}$ concentrations; Urinary $\mathrm{Gb}_{3} \perp$, physiologic concentrations of urinary $\mathrm{Gb}_{3} ; \mathrm{CMP}$, cardiomyopathy; IVS, interventricular septum. 
Table 2. Details of previously known patients with FD(1.-3.).

$\begin{array}{lrlrlll}\text { Sex } & \text { Age Genotype } & \alpha \text {-GAL } & \text { Phenotype } & \mathrm{Gb}_{3}-24: 18 \uparrow & \text { ERT } \\ \text { 1. male } & 35 & \text { p.Q333X } & 3-1 & \begin{array}{l}\text { LVH, emphysema, pain, } \\ \text { angiokeratoma, anhidrosis }\end{array} & \text { yes } \\ \text { 2. male } & 44 & \text { p.Q333X } & 2 & \begin{array}{l}\text { LVH, proteinuria, pain, } \\ \text { fever crisis, tinnitus }\end{array} & \text { yes } & \text { yes } \\ \text { 3. female } & 66 & \begin{array}{l}\text { No mutation } \\ \text { detected }\end{array} & 74-57 & \text { Pain } & \text { no } & \text { yes } \\ \text { LVH, left ventricular hypertrophy. } & & & \end{array}$

\section{Discussion}

This is the first case finding study for FD in a cohort with LVH of variable severity using urinary $\mathrm{Gb}_{3}$ isoform measurement. In 2596 patients referred to the echocardiography laboratory in a tertiary care center we could not identify a disease-causing GLA mutation.

In previous studies (table 3 ), attributable to different inclusion criteria, the prevalence of FD in cohorts at risk ranged between 0 and $12 \%$ (table 3 ). Elliot $e t$ al. published a prevalence of $0.5 \%$ in patients with hypertrophic cardiomyopathy. However, the authors concluded that restricted inclusion criteria underestimate the prevalence of FD and "that there may still be thousands of patients [...] with FD who remain undiagnosed" [15]. Following this hypothesis, our study cohort comprised patients with a various severity of $\mathrm{LVH}$, including mild or moderate $\mathrm{LVH}$ (table 1). Cardiac involvement in FD presents heterogeneously: In 139 FD patients not on enzyme replacement therapy (mean age $43.1 \pm 12.6$ years) about $60 \%$ had a history of cardiovascular symptoms, including dyspnea angina, chest pain, edema, arterial hypertension or a murmur, however the mean IVS thickness in this cohort was only $13.3( \pm 3.4) \mathrm{mm}$ for females and $14.9( \pm 4.1) \mathrm{mm}$ for males. Thirty-one percent had arterial hypertension, although the cohort was relatively young [16]. In the Fabry outcome survey (FOS) LVH was present in only $33 \%$ of untreated females and $53 \%$ of untreated males. LVH was significantly associated with cardiac symptoms, arrhythmias, and valvular disease, emphasizing the unspecific cardiac presentation in FD in the majority of cases [17]. Accordingly, patients with signs or symptoms of cardiovascular disease were not excluded in our study.

Table 3. Previous studies attributable to different inclusion criteria investigating the prevalence of FD in cohorts at risk.

\begin{tabular}{|c|c|c|c|c|c|}
\hline Study & Year & $\mathbf{N}$ (females) & Screening criteria & Screening method & AFD \\
\hline Nakao S. et al. [7] & 1995 & $230(0 \%)$ & LVH (MLVWT $\geq 13 \mathrm{~mm})$ & AGAL activity (plasma) & $7(3 \%)^{*}$ \\
\hline Sachdev B. et al. [8] & 2002 & $153(0 \%)$ & Unexplained LVH (MLVWT $\geq 13 \mathrm{~mm})$ & Genetic analysis & $5(3 \%)^{\dagger}$ \\
\hline Ommen S. et al. [24] & 2003 & $100(66 \%)$ & Unexplained severe HCMP & Myoectomy tissue, TEM & $0^{\ddagger}$ \\
\hline Stöllberger C. et al. [25] & 2003 & $26(0)$ & $\begin{array}{l}\text { Left ventricular hypertrabeculation/ } \\
\text { noncompaction }\end{array}$ & AGAL activity (leukocytes) & 0 \\
\hline Chimenti C. et al. [9] & 2004 & $34(100 \%)$ & Unexplained HCMP & $\begin{array}{l}\text { Endomyocardial biopsy, } \\
\text { AGAL activity (leukocytes) }\end{array}$ & $4(12 \%)$ \\
\hline Arad M. et al. [10] & 2005 & $75(40 \%)$ & Unexplained LVH & Genetic analysis & 0 \\
\hline Morita H. et al. [11] & 2006 & $1862(52 \%)$ & Unexplained LVH & Genetic analysis & $0^{+}$ \\
\hline Monserrat L. et al. [12] & 2007 & $508(35 \%)$ & HCMP & AGAL activity (leukocytes) & $5(1 \%)$ \\
\hline Hagège A. et al. [13] & 2011 & $392(29 \%)$ & Unexplained LVH (MLVWT $\geq 15 \mathrm{~mm}$ ) & AGAL activity (plasma) & $4(1 \cdot 5 \%)$ \\
\hline Elliott P. et al. [15] & 2011 & $1386(36 \%)$ & $\begin{array}{l}\text { Unexplained } \mathrm{LVH}(\mathrm{MLVWT} \geq 15 \mathrm{~mm}) \\
\text { males aged } \geq 35 \mathrm{a} \text {, females aged } \geq 40 \mathrm{a}\end{array}$ & Genetic analysis & $7(0 \cdot 5 \%)$ \\
\hline Havndrup O. et al.[14] & 2012 & $90(37 \%)$ & HCMP & Genetic analysis & $2(+1)(2 \%)^{8}$ \\
\hline Terryn W. et al. [26] & 2012 & $540(33 \%)$ & Unexplained LVH & AGAL activity (leukocytes) & $5(1 \%)$ \\
\hline Mawatari K. et al.[27] & 2012 & $730(100 \%)$ & LVH (MLVWT $\geq 13 \mathrm{~mm})$ & AGAL activity (plasma) & 0 \\
\hline Palecek T. et al. [28] & 2014 & $100(0)$ & Unexplained LVH (MLVWT $\geq 13 \mathrm{~mm}$ ) & AGAL activity & $4(4 \%)$ \\
\hline
\end{tabular}

LVH, left ventricular hypertrophy; MLVWT, maximal left ventricular wall thickness; AGAL, $\alpha$-galactosidase A; HCMP, hypertrophic cardiomyopathy; a, years; TEM, transmission electron microscopy. ${ }^{*}$ Disease-causing mutation could only be identified in 2 subjects. ${ }^{\dagger}$ Result modified by the authors as the p.D313Y sequence variant was accounted to be disease-causing in the published paper. ${ }^{\ddagger}$ No genetic testing was performed. $\S_{\text {The }}$ p.N139S sequence variant is very likely non-disease causing. 
This is the first study that used urinary $\mathrm{Gb}_{3}$ isoform measurements as a case finding tool. Compared to blood sampling, urine testing is easily applied, non-invasive, and cost-saving, especially in large cohorts. Increased $\mathrm{Gb}_{3}$ excretion is a specific feature of FD, and therefore would render this approach superior for primary screening of large cohorts as proposed by several authors [18]. Paschke et al. demonstrated that measuring $\mathrm{Gb}_{3}$ isoforms enables reliable identification of also female subjects [19]. This can be explained by the method itself: while female FD patients excrete a lower amount of total $\mathrm{Gb}_{3}$ compared to males, the proportion of the $\mathrm{Gb}_{3}-24$ isoform is elevated compared to the other isoforms. Since $\mathrm{Gb}_{3}-18$ is steadily excreted over the day it can be used to identify higher amounts of $\mathrm{Gb}_{3}-24$ in relation to Gb3-18 and therefore emphasize the disproportion of $\mathrm{Gb}_{3}$ isoforms. In the present study 99 patients exceeded the predefined cut-off $\mathrm{Gb}_{3}$ ratio and hence, FD was suspected, but later excluded by enzymatic and genetic testing.

In the cohort examined by Paschke et al. the sensitivity and specificity was $86 \%$ (95\% CI: $68 \%$ to 96\%) and $96 \%$ (95\% CI: $94 \%$ to $98 \%$ ), respectively, which was considered adequate for a case-finding study [19]. In our study the number of false positive subjects was $4 \%$, but the significance of elevated $\mathrm{Gb}_{3}$ ratios in these patients is yet unclear. Recently, Schiffmann et al. found out that increased $\mathrm{Gb}_{3}$ levels were associated with increased risk of death in patients with heart disease [21]. Recently, we evaluated interfering parameters in determination of urinary $\mathrm{Gb}_{3}$ in 602 subjects with chronic kidney disease. The $\mathrm{Gb}_{3}$ isoform ratio was unaffected by leukocyturia, hematuria, bacteriuria, proteinuria, and gender as well as renal function. In contrast, total urinary $\mathrm{Gb}_{3}$ was higher in subjects with a higher load of leukocytes and bacteria and in women in general, rendering it inferior to the $\mathrm{Gb}_{3}$ isoform ratio as screening method [22]. Additionally, this gives good evidence that mild urinary $\mathrm{Gb}_{3}$ elevation is not limited to cardiac patients.

\section{Study Limitations}

The applied urinary testing method comprised several limitations in our study: Urinary $\mathrm{Gb}_{3}$ excretion is dependent on the type of mutation and thus lower in subjects with milder phenotypes. Consequently, one female subject with previously diagnosed FD (carrying an unknown GLA alteration) was not detected in our study. Moreover, she received enzyme replacement therapy, which is well known to reduce urinary $\mathrm{Gb}_{3}$ excretion. Noteworthy, this is in contrast to the pilot study used to calculate the cut-off values for the applied screening method, and in which female FD patients were not treated with enzyme replacement therapy. Further on, it was previously described that some subjects comprising missense mutation with residual enzyme activity do neither excrete $\mathrm{Gb}_{3}$ nor lyso- $\mathrm{Gb}_{3}[23]$. These factors limited the accuracy of the applied urinary screening test in this cohort. In $30 \%$ of the subjects with elevated $\mathrm{Gb}_{3}$ isoform ratio FD presence was excluded based solely on medical history, which is of limited reliability. The rate of drop-outs and loss to follow-up altogether was $1.1 \%$, which is not unlikely in a case-finding study.

\section{Conclusion}

In a non-selected cohort of patients with left ventricular hypertrophy of variable severity urinary Gb3 isoform measurement failed to identify new cases of Fabry disease. More restricted inclusion criteria may improve diagnostic accuracy of this method.

\section{Acknowledgments}

The authors wish to acknowledge the help of Beatrix Buschenreithner, Nerajda Cene, MD, Verena Colombo, Ulrike Grojer, and Andrea Schuckert in collecting data and conducting the VIEPAF-study.

The study was funded by a grant from Shire HGT Deutschland GmbH, Berlin, Germany.

\section{Competing Interests}

The authors have declared that no competing interest exists.

\section{References}

1. Zarate YA, Hopkin RJ. Fabry's disease. Lancet 2008; 372: 1427-1435.

2. Mehta A, Ricci R, Widmer U, Dehout F, Garcia de Lorenzo A, Kampmann C, et al. Fabry disease defined: baseline clinical manifestations of 366 patients in the Fabry Outcome Survey. Eur J Clin Invest 2004; 34: 236-242.

3. Mehta A, Beck M, Elliott P, Giugliani R, Linhart A, Sunder-Plassmann G, et al. Enzyme replacement therapy with agalsidase alfa in patients with Fabry's disease: an analysis of registry data. Lancet 2009; 374: 1986-1996.

4. Kotanko P, Kramar R, Devrnja D, Paschke E, Voigtländer T, Auinger M, et al. Results of a nationwide screening for Anderson-Fabry disease among dialysis patients. J Am Soc Nephrol 2004; 15: 1323-1329.

5. Kleinert J, Kotanko P, Spada M, Pagliardini S, Paschke E, Paul K, et al. Anderson-Fabry disease: a case-finding study among male kidney transplant recipients in Austria. Transpl Int 2009; 22: 287-292.

6. Rolfs A, Böttcher T, Zschiesche M, Morris P, Winchester B, Bauer P, et al. Prevalence of Fabry disease in patients with cryptogenic stroke: a prospective study. Lancet 2005; 366: 1794-1796.

7. Nakao S, Takenaka T, Maeda M, Kodama C, Tanaka A, Tahara M, et al. An atypical variant of Fabry's disease in men with left ventricular hypertrophy. $N$ Engl J Med 1995; 333: 288-293.

8. Sachdev B, Takenaka $\mathrm{T}$, Teraguchi H, Tei C, Lee P, McKenna WJ, et al. Prevalence of Anderson-Fabry disease in male patients with late onset hypertrophic cardiomyopathy. Circulation 2002; 105: 1407-1411.

9. Chimenti C, Pieroni M, Morgante E, Antuzzi D, Russo A, Russo MA, et al. Prevalence of Fabry Disease in Female Patients With Late-Onset Hypertrophic Cardiomyopathy. Circulation 2004; 110: 1047-1053.

10. Arad M, Maron BJ, Gorham JM, Johnson WH, Jr., Saul JP, Perez-Atayde AR, et al. Glycogen storage diseases presenting as hypertrophic cardiomyopathy. $N$ Engl J Med 2005; 352: 362-372.

11. Morita H, Larson MG, Barr SC, Vasan RS, O'Donnell CJ, Hirschhorn JN, et al. Single-gene mutations and increased left ventricular wall thickness in the community: the Framingham Heart Study. Circulation 2006; 113: 2697-2705.

12. Monserrat L, Gimeno-Blanes JR, Marín F, Hermida-Prieto M, García-Honrubia A, Pérez I, et al. Prevalence of fabry disease in a cohort of 508 unrelated patients with hypertrophic cardiomyopathy. J Am Coll Cardiol 2007; 50: 2399-2403 
13. Hagège $\mathrm{AA}$, Caudron $\mathrm{E}$, Damy $\mathrm{T}$, Roudaut $\mathrm{R}$, Millaire $\mathrm{A}$, Etchecopar-Chevreuil C, et al. Screening patients with hypertrophic cardiomyopathy for Fabry disease using a filter-paper test: the FOCUS study. Heart 2011; 97: 131-136.

14. Havndrup O, Christiansen M, Stoevring B, Jensen M, Hoffman-Bang J, Andersen PS, et al. Fabry disease mimicking hypertrophic cardiomyopathy: genetic screening needed for establishing the diagnosis in women. Eur J Heart Fail 2012; 12: 535-540.

15. Elliott P, Baker R, Pasquale F, Quarta G, Ebrahim H, Mehta AB, et al. Prevalence of Anderson-Fabry disease in patients with hypertrophic cardiomyopathy: the European Anderson-Fabry Disease survey. Heart 2011; 97: 1957-1960.

16. Wu JC, Ho CY, Skali H, Abichandani R, Wilcox WR, Banikazemi M, et al. Cardiovascular manifestations of Fabry disease: relationships between left ventricular hypertrophy, disease severity, and alpha-galactosidase A activity. Eur Heart J 2010; 31: 1088-1097.

17. Linhart A, Kampmann C, Zamorano JL, Sunder-Plassmann G, Beck M, Mehta A, et al. Cardiac manifestations of Anderson-Fabry disease: results from the international Fabry outcome survey. Eur Heart J 2007; 28: 1228-1235.

18. Auray-Blais C, Millington DS, Young SP, Clarke JT, Schiffmann R. Proposed high-risk screening protocol for Fabry disease in patients with renal and vascular disease. J Inherit Metab Dis 2009; 32: 303-308.

19. Paschke E, Fauler G, Winkler H, Schlagenhauf A, Plecko B, Erwa W, et al. Urinary Total Globotriaosylceramide and Isoforms to Identify Women With Fabry Disease: A Diagnostic Test Study. Am J Kidney Dis 2011; 57: 673-681.

20. Fauler G, Rechberger GN, Devrnja D, Erwa W, Plecko B, Kotanko P, et al. Rapid determination of urinary globotriaosylceramide isoform profiles by electrospray ionization mass spectrometry using stearoyl-d35-globotriaosylceramide as internal standard. Rapid Commun Mass Spectrom 2005; 19: 1499-1506.

21. Schiffmann R, Forni S, Swift C, Brignol N, Wu X, Lockhart DJ, et al. Risk of death in heart disease is associated with elevated urinary globotriaosylceramide. Journal of the American Heart Association 2014; 3: e000394.

22. Gaggl M, Hofer M, Weidner S, Kleinert J, Fauler G, Wallner M, et al. Interfering parameters in the determination of urinary globotriaosylceramide (Gb) in patients with chronic kidney disease. J Nephrol 2015.

23. Auray-Blais C, Ntwari A, Clarke JT, Warnock DG, Oliveira JP, Young SP, et al. How well does urinary lyso-Gb3 function as a biomarker in Fabry disease? Clin Chim Acta 2012; 411: 1906-1914.

24. Ommen SR, Nishimura RA, Edwards WD. Fabry disease: a mimic for obstructive hypertrophic cardiomyopathy? Heart 2003; 89: 929-930.

25. Stöllberger C, Finsterer J, Voigtländer T, Slany J. Is left ventricular hypertrabeculation/ noncompaction a cardiac manifestation of Fabry's disease? Z Kardiol 2003; 92: 966-969.

26. Terryn W, Deschoenmakere G, De Keyser J, Meersseman W, Van Biesen W, Wuyts B, et al. Prevalence of Fabry disease in a predominantly hypertensive population with left ventricular hypertrophy. Int I Cardiol 2013; 167: 2555-2560.

27. Mawatari K, Yasukawa H, Oba T, Nagata T, Togawa T, Tsukimura T, et al. Screening for Fabry disease in patients with left ventricular hypertrophy. Int $J$ Cardiol 2012: http:/ / dx.doi.org/10.1016/j.ijcard.2012.1010.1076.

28. Palecek T, Honzikova J, Poupetova H, Vlaskova H, Kuchynka P, Golan L, et al. Prevalence of Fabry disease in male patients with unexplained left ventricular hypertrophy in primary cardiology practice: prospective Fabry cardiomyopathy screening study (FACSS). J Inherit Metab Dis 2014; 37: 455-460. 